\title{
Cytokines in relation to hCG are significantly altered in asymptomatic women with miscarriage - a pilot study
}

\author{
Alexander Freis ${ }^{{ }^{*}} \mathbb{D}$, Janina Schlegel ${ }^{1}$, Volker Daniel ${ }^{2}$, Julia Jauckus ${ }^{1}$, Thomas Strowitzki $^{1}$ and Ariane Germeyer $^{1}$
}

\begin{abstract}
Background: Spontaneous abortion is one of the most common complications in early pregnancy. A preventive test to identify women who will experience a miscarriage, even before first symptoms occur, is not established. Activation of maternal immunological tolerance seems to be essential for early fetal development and various cytokines have been described in different stages of pregnancy. Therefore, we aimed to investigate if chemokine levels at the time of pregnancy testing relative to human Choriogonadotropin (hCG) are altered in patients who will experience a miscarriage in this pregnancy.

Methods: We obtained blood samples from 39 women. Dependent on the follow-up, patients with a positive pregnancy test were subsequently divided in two groups: ongoing pregnancy $(n=22)$ and miscarriage $(n=17)$ in this pregnancy. Immunological and endocrine profiling of maternal plasma at the time of pregnancy testing (5th week of gestation) was performed for each group at the time of pregnancy test using Multiplex and ELISA analysis.

Results: hCG was significantly decreased in patients with abortion whereas levels of IL-1ra, MIP-1a and TNF-alpha were significantly increased. GCSF/ IL-1 ra-ratio was 1.66-fold increased in patients with ongoing pregnancy. TGFbeta /MIP1a-ratio was significantly 3.45-times higher in patients with miscarriage. Comparing patients with ongoing pregnancy to patients experiencing a miscarriage, we could demonstrate significant alterations of the ratios MIP1a/ hCG, IL-1ra/hCG, TNFalpha/hCG, MCP1/hCG, IL-6/hCG, TPO/hCG and TGF-beta1/hCG. The strongest effects were seen for the ratio MIP1a/hCG, IL-1ra/hCG and TNFalpha/hCG.
\end{abstract}

Conclusions: We have shown that cytokines in relation to hCG after 4 weeks of gestation are significantly altered in women with miscarriage, promising potential as a prognostic biomarker.

Keywords: Miscarriage, Biomarker, Early pregnancy, hCG, Chemokines

\section{Background}

Spontaneous abortion is one of the most common complications in early pregnancy and affects $10-20 \%$ of all pregnancies [1-5]. Symptoms include vaginal bleeding, and/or uterine cramping, but only $28 \%$ of symptomatic patients are experiencing spontaneous abortions later in pregnancy $[6,7]$. In clinical practice, ultrasound is performed to verify the embryos viability [1]. However, as ultrasound cannot determine pregnancy progress, different hormone assessments have been published in order

\footnotetext{
* Correspondence: alexander.freis@med.uni-heidelberg.de ${ }^{1}$ Department of Gynaecological Endocrinology and Fertility Disorders, University Hospital Heidelberg, INF 440, 69120 Heidelberg, Germany Full list of author information is available at the end of the article
}

to help predict pregnancy outcome, such as human chorionic gonadotropin (hCG), progesterone, kisspeptin, activin $\mathrm{A}$, activin $\mathrm{B}$, follistatin, CA-125, pregnancy associated plasma protein A (PAPP-A) or macrophage inhibitory cytokine- $1[1,2,4,6,8-13]$. However, their clinical significance remains fair.

Miscarriage occurs in more than $80 \%$ in the first 12 weeks of gestation and presents an enormous distress for the patient and challenges the medical professionals, especially as pregnancy outcome is difficult to estimate when the patient presents with the first symptoms [1, 2, 4, 13]. Moreover, patients with a previous abortion present with a higher risk of severe complications in the following pregnancy, such as preeclampsia or preterm birth $[2,14,15]$. 
The causes of early pregnancy loss are various, including cytogenetic abnormalities, maternal comorbidities (eg. diabetes mellitus, lupus erythematosus), uterine malformations, smoking as well as inadequate placental development $[2,3]$.

Activation of maternal immunological tolerance seems to be essential for early fetal development and implantation [16] and various cytokines have been described in different stages of pregnancy [17].

For example, lower levels of interleukin 1-receptor antagonist (IL-1ra) prior to embryo transfer were associated with lower pregnancy rates [18]. Higher levels of Thyreoperoxidase (TPO) and lower concentrations of Granulocyte-Colony Stimulating Factor (GCSF) were significantly associated with the risk of spontaneous abortion in women prior to report of miscarriage. Concerning TPO, this effect is not evident starting before approximately 8 weeks of gestation. However, GCSF alone was only predictive when focusing on women with an upcoming miscarriage within 14 days [17]. Furthermore, chemokine ligand 3 (CCL3)/macrophage inflammatory protein 1-alpha (MIP-1a) is recognized as a local chemoattractant for natural killer cells, whose increased levels in decidual tissue are associated with recurrent pregnancy losses in decidual tissue within the first 10 weeks of gestation [19]. In addition, transforming growth factor (TGF) beta-1 is described as an important factor in immunological reactions and immunological tolerance and shows a lower expression in peripheral blood mononuclear cell cultures of women who experience an abortion or biochemical pregnancy, measured at the time before oocyte retrieval. [20]. Furthermore, hCG itself, essential in early pregnancy, cause an increase in regulatory T-cells, has effects on cytokine production, such as an increase in IL-1beta- levels [21], and seems to possess an important role as modulator of immune tolerance during pregnancy [22].

A shift between Th1- and Th2- guided immunological response also seems to play an important role in early pregnancy. The cytokine balance towards Th2-cytokines like Interleukin (IL)-6, as well as tumor necrosis factor (TNF)-alpha is considered important in early pregnancy in maternal blood $[23,24]$. Various factors have their influence on this balance, eg. CCL2 or MIP-1 is considered to cause a shift towards the Th2-response of decidual leukocytes [25]. However, in contrary to this observation, serum levels of CCL-2/macrophage inflammatory protein (MIP-1) were elevated in women with recurrent spontaneous abortion (RSA) after spontaneous abortion occurred [26], whereas other studies did not see any significant alteration [5].

Most of the currently available studies evaluate symptomatic women, therefore we are the first ones trying to develop biomarkers that are usable even before patients become symptomatic in order to identify women who will experience a miscarriage.

The development of a predictive test for miscarriages can be a helpful instrument to reassure patients on one hand, but also to identify patients who will develop a miscarriage on the other hand and therefore not to prolong unnecessary suffering of the patient. Last, but not least, it may someday lead to potential therapies for such patients [11].

\section{Methods}

The prospective pilot study was approved by Heidelberg University Ethical Committee (protocol S-243/2015) and the experimental testing complied with the principles specified in the Declaration of Helsinki.

Blood samples were obtained at the time of pregnancy testing (5th week of gestation) after informed consent from women who underwent ovarian hyperstimulation to perform in vitro fertilization by IVF or ICSI during the period $05 / 15-05 / 16$ at the University Hospital in Heidelberg, Germany.

Exclusion criteria were autoimmune diseases, essential hypertonia, diabetes mellitus or the intake of confounding medication (e.g. acetylsalicylic acid).

Dependent on the follow-up, patients with a positive pregnancy test were subsequently divided in two groups: (1) patients with ongoing pregnancy $(n=22)$ and (2) patients with miscarriage (missed abortion, abortus incompletus or abortus completus, $n=17$ ) in the first trimester of this pregnancy.

Immunological and endocrine profiling of maternal plasma of women with and without miscarriage was performed for each group at the time of pregnancy testing, in order to predict pregnancy outcome.

\section{Determination of cytokine levels}

IL-6, TNFalpha, (Luminex Performance Assay, Human High Sensitivity Cytokine Base Kit A; R\&D systems, Wiesbaden, Germany), IL-1ra, CCL2/MCP-1, CCL3/ MIP-1 alpha, G-CSF, Thrombopoietin/Tpo (Human Luminex Performance Assay Base Kit, Panel A; R\&D systems, Wiesbaden, Germany), TGF-beta 1 (Luminex Performance Assay 3-plex Kit; R\&D systems, Wiesbaden, Germany) were determined in 39 samples using Multiplex and ELISA analysis. Assays were performed according to the instructions of the manufacturer. Measurements were performed as $\mathrm{pg} / \mathrm{ml}$ and values given as mean+/- SEM.

\section{Determination of hCG-levels}

hCG-levels (mIU/ml, mean+/- SEM) were measured routinely in clinical practice at the time of pregnancy testing from central laboratory, University Hospital Heidelberg, Germany. 


\section{Statistics}

Statistical analysis was performed with SPSS $^{\oplus}$ Version 24, IBM, Armonk, USA. $p \leq 0.05$ was considered to be significant.

\section{Results}

There was no significant difference in age (33.64 \pm 6.49 years vs. $33.94 \pm 4.4$ years), nor in body mass index in group 1 and 2 with $23.81 \pm 4.29 \mathrm{~kg} / \mathrm{m}^{2}$ in group 1 vs. $26.48 \pm$ $5.27 \mathrm{~kg} / \mathrm{m}^{2}$ in group 2 (Table 1) or transfer day (Table 2).

hCG-results and immunological profiles of patients with ongoing pregnancy $(n=22, \mathrm{Nr} .1-22)$ and miscarriage ( $n=17$, Nr. 23-39) were analysed. Quantitative difference in GCSF-, MCP-1-, TPO- or IL-6-expression showed a trend towards a change in values, however did not reach statistical significance.

hCG levels, were significantly decreased in patients with miscarriage compared to those with ongoing pregnancy $(151.75 \pm 25.29 \mathrm{IU} / \mathrm{l}$ vs. $351.27 \pm 111.02 \mathrm{IU} / \mathrm{l}, p<$ $0.05)$ However, they were within normal limits and therefore not predictive for pregnancy outcome.

Similarly, levels of IL-1ra $(655.80 \pm 78.80 \mathrm{pg} / \mathrm{ml}$ vs. $398.69 \pm$ $32.73 \mathrm{pg} / \mathrm{ml}, p<0.01)$, MIP-1a $(73.74 \pm 9.91 \mathrm{pg} / \mathrm{ml}$ vs. $34.20 \pm$ $8.25 \mathrm{pg} / \mathrm{ml}, p<0.01)$ and TNF-alpha $(5.11 \pm 0.40 \mathrm{pg} / \mathrm{ml}$ vs. $4.00 \pm 0.26 \mathrm{pg} / \mathrm{ml}, p<0.05)$ were significantly increased.

In order to get a potentially more stable predictor, we investigated if the relative expressions of immunological factors among themselves show a significant alteration.

Here, we found that the ratio of GCSF to IL-1ra was 1.66 -fold decreased $(p<0.05)$ in patients suffering from miscarriage $(0.043 \pm 0.005)$ compared to patients with ongoing pregnancy $(0.072 \pm 0.009 ; p<0.05)$. In addition, the ratio of MIP1a to TGF-beta was 3,45-times higher in patients with miscarriages $(0.012 \pm 0.005)$ compared to patients without ongoing pregnancy $(0.004 \pm 0.001 ; p<$ 0.05 ) (data are shown in Table 3 ). The other relative expressions of the different cytokines analysed did not show significant changes.

Due to the observation, that patients with miscarriage showed lower levels of hCG and increased levels in immunological factors at the same time, we investigated if we get a higher predictive value, if we analyse the relative expression of immunological factors compared to hCG (Table 4).

Table 1 Patient characteristics. There was no significant difference in age or BMl between the two groups. All values are given in mean \pm STD

\begin{tabular}{llll}
\hline & Ongoing pregnancy & Abortion & $p$-value \\
\hline Age (years) & $33.64 \pm 6.49$ & $33.94 \pm 4.4$ & 0.87 \\
BMl (kg/m2) & $23.81 \pm 4.29$ & $26.48 \pm 5.27$ & 0.12 \\
\hline
\end{tabular}

Comparing patients with ongoing pregnancy to patients experiencing a miscarriage, we could demonstrate significant alterations of the ratios MIP1a/hCG $(0.16 \pm$ $0.04 \mathrm{pg} / \mathrm{mIU}$ vs. $1.02 \pm 0.38 \mathrm{pg} / \mathrm{mIU}, p<0.05)$, IL-1ra/ hCG $(2.22 \pm 0.72 \mathrm{pg} / \mathrm{mIU}$ vs. $7.83 \pm 2.30 \mathrm{pg} / \mathrm{mIU}, p<$ $0.05)$, TNFalpha /hCG $(0.02 \pm 0.01 \mathrm{pg} / \mathrm{mIU}$ vs. $0.07 \pm$ $0.02 \mathrm{pg} / \mathrm{mIU}, p<0.05), \mathrm{MCP} 1 / \mathrm{hCG}(0.50 \pm 0.16 \mathrm{pg} / \mathrm{mIU}$ vs. $1.44 \pm 0.40 \mathrm{pg} / \mathrm{mIU}, p<0.05)$, IL-6/hCG $(0.007 \pm$ $0.002 \mathrm{pg} / \mathrm{mIU}$ vs $0.016 \pm 0.003 \mathrm{pg} / \mathrm{mIU}, p<0.05), \mathrm{TPO} /$ hCG $(2.50 \pm 0.70 \mathrm{pg} / \mathrm{mIU}$ vs. $5.47 \pm 1.31 \mathrm{pg} / \mathrm{mIU}, p<$ $0.05)$ and TGF-beta1/hCG $(68.04 \pm 22.37 \mathrm{pg} / \mathrm{mIU}$ vs. $149.35 \pm 33.89 \mathrm{pg} / \mathrm{mIU}, p<0.05)$.

Altogether, we observe a significant alteration towards the immunological factor in relation to hCG levels in patients, who experience a miscarriage in their course of pregnancy.

The strongest effects were seen for the ratio MIP1a/ hCG (ratio 0.15) for patients with ongoing pregnancy compared to patients with abortion, IL-1ra (ratio 0.28) and TNFalpha (ratio 0.29).

\section{Discussion}

Spontaneous abortion is one of the most common complications in early pregnancy and affects $10-20 \%$ of all pregnancies [1-5].

There is currently no successful therapeutical approach established, although various approaches have been tested $[5,27]$.

The development of an early-screening test to identify patients who are at risk to suffer from abortion in the actual pregnancy can be useful in manyfold ways: a miscarriage presents an enormous distress for the patient and a predictive test with a negative result could be used to reassure anxious patients $[1,2,4,5,13]$. On the other hand, a predictive test with a positive result can warn the patients in a very early stage of pregnancy [5], and will prohibit unnecessary prolongation of the current pregnancy by supplementation of high doses of progesterone, as progesterone prevents bleeding.

Most of the studies trying to establish biomarkers to follow this approach include symptomatic women at a later stage of pregnancy. One of the most interesting aspects concerning our data is the fact that we discovered in total 3 absolute and 9 relative alterations in immunological profile parameters of asymptomatic patients at the time of first pregnancy testing, that could present a very helpful tool in clinical practice to discover patients at risk even before first symptoms occur.

Another interesting point in screening for altered potential biomarkers is the fact that the discovered proteins in maternal plasma may help to identify potential therapeutical targets in the long run $[5,11]$.

Cytokines play an important role in implantation and early pregnancy $[16,28]$. For example, IL-1 
Table 2 Embryo quality and day of embryo transfer

\begin{tabular}{|c|c|c|c|c|}
\hline$\overline{\mathrm{Nr}}$ & Abortion & Ongoing pregnacy & Embryo quality & Embryo transfer \\
\hline 1 & no & yes & $6 C, 8 B$ & day 3 \\
\hline 2 & no & yes & $4 \mathrm{AA}, 4 \mathrm{AA}$ & day 5 \\
\hline 3 & no & yes & $4 A B, 3 A A$ & day 5 \\
\hline 4 & no & yes & $2 \mathrm{~A}, 4 \mathrm{~B}$ & day 2 \\
\hline 5 & no & yes & Morula, blastocyst 1 & day 5 \\
\hline 6 & no & yes & 4BA, blastocyst 1 & day 5 \\
\hline 7 & no & yes & 4AA hatch & day 5 \\
\hline 8 & no & yes & $5 B$ & day 2 \\
\hline 9 & no & yes & Blastocyst 1 & day 5 \\
\hline 10 & no & yes & $9 \mathrm{~B}$ & day 3 \\
\hline 11 & no & yes & $4 A B, 3 A B$ & day 5 \\
\hline 12 & no & yes & $4 \mathrm{AA}, 4 \mathrm{AA}$ & day 5 \\
\hline 13 & no & yes & $12 \mathrm{~B}$ & day 4 \\
\hline 14 & no & yes & $3 B A$ & day 5 \\
\hline 15 & no & yes & Morula & day 4 \\
\hline 16 & no & yes & $4 A B, 3 A B$ & day 5 \\
\hline 17 & no & yes & Blastocyst 1 & day 5 \\
\hline 18 & no & yes & Blastocyst 1 & day 4 \\
\hline 19 & no & yes & Morula, Morula & day 4 \\
\hline 20 & no & yes & $4 \mathrm{~A}$ & day 2 \\
\hline 21 & no & yes & $6 C, 4 B$ & day 3 \\
\hline 22 & no & yes & $4 \mathrm{BB}, 4 \mathrm{BB}$ & day 5 \\
\hline 23 & yes & no & Blastocyst 1, blastocyst 2 & day 4 \\
\hline 24 & yes & no & 3AB, blastocyst 1 & day 5 \\
\hline 25 & yes & no & 3BB & day 5 \\
\hline 26 & yes & no & $4 \mathrm{AA}, 4 \mathrm{AA}$ & day 5 \\
\hline 27 & yes & no & $4 \mathrm{~B}$ & day 2 \\
\hline 28 & yes & no & $11 \mathrm{~A}$ & day 4 \\
\hline 29 & yes & no & Blastocyst 1 , blastocyst 2 & day 5 \\
\hline 30 & yes & no & $4 \mathrm{~A}, 4 \mathrm{~A}$ & day 2 \\
\hline 31 & yes & no & $4 A A, 3 A A$ & day 5 \\
\hline 32 & yes & no & $2 \mathrm{~A}$ & day 2 \\
\hline 33 & yes & no & 4AA, Blastocyst 1 & day 5 \\
\hline 34 & yes & no & $8 \mathrm{~A}, 8 \mathrm{C}$ & day 5 \\
\hline 35 & yes & no & $8 \mathrm{~B}, 7 \mathrm{C}$ & day 2 \\
\hline 36 & yes & no & Blastocyst 1, blastocyst 2 & day 5 \\
\hline 37 & yes & no & $4 \mathrm{BA}, 3 \mathrm{AA}$ & day 4 \\
\hline 38 & yes & no & $4 \mathrm{AA}, 4 \mathrm{AA}$ & day 3 \\
\hline 39 & yes & no & $9 \mathrm{C}, 5 \mathrm{~B}, 8 \mathrm{C}$ & day 2 \\
\hline
\end{tabular}


Table 3 Significant alterations of relative immunological profile. GCSF, IL-1 ra, MIP1a and TGF-beta were assessed in pg/ml

\begin{tabular}{lll}
\hline Ratio & GCSF/L-1 ra & MIP1a /TGF-beta 1 \\
\hline mean \pm SEM (ongoing pregnancy) & $0.072 \pm 0.009$ & $0.004 \pm 0.001$ \\
mean \pm SEM (abortion) & $0.043 \pm 0.005$ & $0.012 \pm 0.005$ \\
Ratio & 1.657 & 0.293 \\
p-value & $<0.05$ & $<0.05$ \\
\hline
\end{tabular}

receptors have been shown to be located on the early human embryo, emphasizing the important role of IL1-ra in early pregnancy [18]. Therefore, we aimed to establish chemokines as biomarkers at the time of pregnancy testing, some of which were found to be changed in patients with proven abortions.

Especially MIP1a, IL-1ra and TNF alpha showed promising results: not only absolute values were altered, additionally we could demonstrate altered relative expression changes, when put in relation to hCG, potentially making them even more predictive for pregnancy outcome in such an early phase.

MCP1 (aka CCL-2) is discussed controversially in the literature: it is considered to cause a shift towards Th2-response, which seems to present an important process in early pregnancy [23-25]. However, contrary to this observation, serum levels of MCP1 in early pregnancy were higher in women with RSA [26], whereas other studies did not see any significant alteration [5].

With our data we can rather support the observation that MCP1 does not show any change concerning the absolute values in patients with abortion during pregnancy. However, the ratio of MCP1/hCG varies between women with ongoing pregnancy and women suffering from abortion at the time of pregnancy testing already. This emphasizes the usefulness of the chemokine/hCG ratios compared to absolute levels.

TNF-alpha also favours a shift towards Th2-guided immune response. Despite this fact, our data does not answer the question which immunological pathway is dominant in early pregnancy or abortion.
Other factors, such as TPO or IL- 6 that showed alterations at other time points in pregnancy [17, 20], were not significantly altered regarding the absolute expression at this very early time point in pregnancy, but showed altered expression when put in relation to $\mathrm{hCG}$.

This observation may be contributed to the fact that absolute alterations may be already present at time of pregnancy testing but do not show an effect that allows to reach statistical significance with a small sample size.

To screen for promising biomarkers at this very early stage in pregnancy, we tent to enhance the prognostic marker for later abortion by examining a cytokines/ hCG correlation, leading to changes in clinical management. These ratios showed very promising results and were, to our knowledge, not described elsewhere in the literature. Due to the fact that two potentially altered proteins are included in this ratio, we think that these ratios are more predictive for pregnancy outcome than absolute cytokine or hCG expression levels and present therefore a high potential for the use as a biomarker. Furthermore, even though hCG levels were found to be significantly decreased in patients with abortion compared to those with ongoing pregnancy at the time of pregnancy testing, their levels are within normal limits and can therefore not be used as predictive factor of pregnancy outcome.

The limitations of this study are its small sample size and the fact, that we only detected protein in maternal plasma with no further validation technique. Therefore, our results require further validation after power calculation in order evaluate the different ratios. Furthermore, it is worth to investigate if an index involving different chemokines can be created.

Our study included patients after ART solely. We can't exclude that these findings can be transmitted to patients who conceived spontaneously. However, as ART seems to influence cytokine profile, our findings can be specific for patients following in-vitro-fertilization [29].

Table 4 Alterations in immunological profile relative to hCG-levels. MIP1a, IL-1ra, TNF alpha, MCP1, IL-6, TPO and TGF-beta1 were assessed in pg/ml, hCG in $\mathrm{mlU} / \mathrm{ml}$

\begin{tabular}{|c|c|c|c|c|c|c|c|}
\hline Ratio & $\begin{array}{l}\text { MIP1a }(\mathrm{pg} / \mathrm{ml}) / \\
\text { hCG (mlE/ml) }\end{array}$ & $\begin{array}{l}\text { IL-1ra }(\mathrm{pg} / \mathrm{ml}) / \\
\text { hCG (mlE/ml) }\end{array}$ & $\begin{array}{l}\text { TNF alpha(pg/ml)/ } \\
\text { hCG (mlE/ml) }\end{array}$ & $\begin{array}{l}\mathrm{MCP} 1(\mathrm{pg} / \mathrm{ml}) / \\
\mathrm{hCG}(\mathrm{mlE} / \mathrm{ml})\end{array}$ & $\begin{array}{l}\text { IL-6 (pg/ml)/ } \\
\text { hCG (mlE/ml) }\end{array}$ & $\begin{array}{l}\text { TPO }(\mathrm{pg} / \mathrm{ml}) / \\
\mathrm{hCG}(\mathrm{mlE} / \mathrm{ml})\end{array}$ & $\begin{array}{l}\text { TGF-beta1 } \\
(\mathrm{pg} / \mathrm{ml}) / \\
\text { hCG(mlE/ml) } \\
\end{array}$ \\
\hline $\begin{array}{l}\text { mean } \pm \text { SEM } \\
\text { (ongoing pregnancy) }\end{array}$ & $0.16 \pm 0.04$ & $2.22 \pm 0.72$ & $0.02 \pm 0.01$ & $0.5 \pm 0.16$ & $0.007 \pm 0.002$ & $2.50 \pm 0.70$ & $68.04 \pm 22.37$ \\
\hline $\begin{array}{l}\text { mean } \pm \text { SEM } \\
\text { (abortion) }\end{array}$ & $1.02 \pm 0.38$ & $7.83 \pm 2.30$ & $0.07 \pm 0.02$ & $1.44 \pm 0.40$ & $0.016 \pm 0.003$ & $5.47 \pm 1.31$ & $149.35 \pm 33.89$ \\
\hline Ratio & 0.15 & 0.28 & 0.29 & 0.35 & 0.44 & 0.45 & 0.45 \\
\hline$p$-value & $<0.05$ & $<0.05$ & $<0.05$ & $<0.05$ & $<0.05$ & $<0.05$ & $<0.05$ \\
\hline
\end{tabular}




\section{Conclusion}

In conclusion, we have shown that cytokines in relation to hCG, as well as the ratio of GCSF/IL-1ra and MIP1a/ TGF-beta1 after 4 weeks of gestation are significantly altered in women with abortion, indicating their potential use as a prognostic biomarker. Particularly the ratios of MIP1a, IL-1ra and TNF alpha to hCG show very promising results.

\section{Abbrevations \\ CCL: Chemokine (C-C Motif) ligand; ELISA: Enzyme-linked Immunosorbent Assay; GCSF: Granulocyte-colony stimulating factor; hCG: Human choriogonadotropin; ICSI: Intracytoplasmic sperm injection; IL: Interleukin; IVF: In vitro fertilization; MIP: Macrophage inflammatory protein; PAPP- A: Pregnancy associated plasma protein A; RSA: Recurrent spontaneous abortion; SEM: Standard error of mean; TGF: Transforming growth factor; TNF: Tumor necrosis factor; TPO: Thyreoperoxidase}

\section{Acknowledgements}

We want to acknowledge the skillful technical assistance of Martina KutscheBauer und Regina Seemuth. We acknowledge financial support by Deutsche Forschungsgemeinschaft and Ruprecht-Karls-Universität Heidelberg within the funding programme Open Access Publishing.

\section{Funding}

The FRONTIER Exzellenzinitiative of the University Heidelberg funded this study.

\section{Availability of data and materials}

The data sets used and/or analysed during the current study are available from the corresponding author on reasonable request.

\section{Authors' contributions}

$A F, V D$ and $A G$ designed the study. AF, JS and JJ conducted the sample collection and compiled the data. AF, JJ, AG and VD analyzed and interpreted chemokine-levels using ELISA. AF, VD and AG performed statistical analysis and AF, TS and AG generated the manuscript. All authors read and approved the final manuscript.

\section{Ethics approval and consent to participate}

The study was approved by the Ethical Committee of the Heidelberg University (protocol S-243/2015). All patients included gave their written agreement after informed consent.

\section{Consent for publication}

Written informed consent for publication was obtained.

\section{Competing interests}

The University Heidelberg is filing a patent on the published ratios.

\section{Publisher's Note}

Springer Nature remains neutral with regard to jurisdictional claims in published maps and institutional affiliations.

\section{Author details}

${ }^{1}$ Department of Gynaecological Endocrinology and Fertility Disorders, University Hospital Heidelberg, INF 440, 69120 Heidelberg, Germany. ${ }^{2}$ Transplantation-Immunology, Institute of Immunology, University Hospital Heidelberg, Im Neuenheimer Feld 305, 69120 Heidelberg, Germany.

Received: 30 June 2018 Accepted: 25 September 2018

Published online: 28 September 2018

\section{References}

1. Pillai RN, Konje JC, Tincello DG, Potdar N. Role of serum biomarkers in the prediction of outcome in women with threatened miscarriage: a systematic review and diagnostic accuracy meta-analysis. Hum Reprod Update. 2016; 22(2):228-39.
2. Jayasena CN, Abbara A, Izzi-Engbeaya C, Comninos AN, Harvey RA, Gonzalez Maffe J, et al. Reduced levels of plasma Kisspeptin during the antenatal booking visit are associated with increased risk of miscarriage. J Clin Endocrinol Metab. 2014;99:E2652-60.

3. Morley LC, Simpson N, Tang T. In: Tang T, editor. Human chorionic gonadotrophin (hCG) for preventing miscarriage. Chichester: Wiley; 2013. p. 1-33.

4. Hanita O, Roslina O, Nor AM. Maternal level of pregnancy-associated plasma protein a as a predictor of pregnancy failure in threatened abortion. Malaysian J Pathol. 2012;34:145-51.

5. Hannan NJ, Bambang K, Kaitu'U-Lino TJ, Konje JC, Tong S. A bioplex analysis of cytokines and chemokines in first trimester maternal plasma to screen for predictors of miscarriage. PLoS One. 2014;9:e93320-7.

6. Duan L, Yan D, Zeng W, Yang X, Wei Q. Predictive power progesterone combined with beta human chorionic gonadotropin measurements in the outcome of threatened miscarriage. Arch Gynecol Obstet. 2010;283:431-5.

7. Sapra KJ, Buck Louis GM, Sundaram R, Joseph KS, Bates LM, Galea S, et al. Signs and symptoms associated with early pregnancy loss: findings from a population-based preconception cohort. Hum Reprod. 2016;31:887-96.

8. Warrick J, Gronowski A, Moffett C, Zhao Q, Bishop E, Woodworth A. Serum activin $A$ does not predict ectopic pregnancy as a single measurement test, alone or as part of a multi-marker panel including progesterone and hCG. Clinica Chimica Acta. 2012;413:707-11.

9. Daponte A, Deligeoroglou E, Garas A, Pournaras S, Hadjichristodoulou C, Messinis IE. Activin A and follistatin as biomarkers for ectopic pregnancy and missed abortion. Dis Markers. 2013;35:497-503.

10. Dhiman P, Senthilkumar GP, Rajendiran S, Sivaraman K, Soundararaghavan S, Kulandhasamy M. Serum activin B concentration as predictive biomarker for ectopic pregnancy. Clin Biochem. 2016;49:609-12.

11. Tong S, Ngian G-L, Onwude JL, Permezel M, Saglam B, Hay S, et al. Diagnostic accuracy of maternal serum macrophage inhibitory Cytokine-1 and pregnancy-associated plasma protein-a at 6-10 weeks of gestation to predict miscarriage. Obstet Gynecol. 2012;119:1000-8.

12. Barnhart KT, Guo W, Cary MS, Morse CB, Chung K, Takacs P, et al. Differences in serum human chorionic gonadotropin rise in early pregnancy by race and value at presentation. Obstet Gynecol. 2016;128:504-11.

13. Al Mohamady M, Fattah GA, Elkattan E, Bayoumy R, Hamed D. Correlation of serum CA-125 and progesterone levels with ultrasound markers in the prediction of pregnancy outcome in threatened miscarriage. Int J Fertil Steril. 2016;9:506-11.

14. van Oppenraaij RHF, Jauniaux E, Christiansen OB, Horcajadas JA, Farquharson RG, Exalto N, et al. Predicting adverse obstetric outcome after early pregnancy events and complications: a review. Hum Reprod Update. 2009:15:409-21.

15. Townend J, Shetty A, Campbell D, Bhattacharya S. Does miscarriage in an initial pregnancy lead to adverse obstetric and perinatal outcomes in the next continuing pregnancy? BJOG. 2008;115:1623-9.

16. Raghupathy R. Th I -type immunity is incompatible successful pregnancy. Immunol Today. 1997;18:1-5.

17. Whitcomb BW, Schisterman EF, Klebanoff MA, Baumgarten M, Luo X, Chegini N. Circulating levels of cytokines during pregnancy; thrombopoietin is elevated in miscarriage. Fertil Steril. 2008;89(6):1795-802.

18. Spandorfer SD, Neuer A, Liu HC, Rosenwaks Z, Witkin SS. Involvement of Interleukin-1 and the Interleukin-1 receptor antagonist in in vitro embryo development among women undergoing in vitro fertilization-embryo transfer. J Assist Reprod Genet. 2003:20:502-5.

19. Park DW, Lee HJ, Park CW, Hong SR, Kwak-Kim J, Yang KM. Peripheral blood NK cells reflect changes in Decidual NK cells in women with recurrent miscarriages. Am J Reprod Immunol. 2010;63:173-80.

20. Ginsburg ES, Xiao L, Gargiulo AR, Kung F-T, Politch JA, Schust DJ, et al. Thelper 2 and 3 type immunity to trophoblast in successful in vitro fertilization-embryo transfer. Fertil Steril. 2005;83:1659-64.

21. Furcron A-E, Romero R, Mial TN, Balancio A, Panaitescu B, Hassan SS, et al. Human chorionic gonadotropin has anti-inflammatory effects at the maternal-fetal Interface and prevents endotoxin-induced preterm birth, but causes dystocia and fetal compromise in Mice1. Biol Reprod. 2016;94:421-13.

22. Schumacher A, Heinze K, Witte J, Poloski E, Linzke N, Woidacki K, et al. Human chorionic gonadotropin as a central regulator of pregnancy immune tolerance. J Immunol. 2013;190:2650-8.

23. Lee YL, Ng HP, Lau KS, Liu WM, WS O, Yeung WS, Kung AW. Increased fetal abortion rate in autoimmune thyroid disease is related to circulating TPO 
autoantibodies in an autoimmune thyroiditis animal model. Fertility and Sterility. 2009;91((5):210-9.

24. Raghupathy R. Pregnancy: success and failure within the Th1/Th2/Th3 paradigm. Semin Immunol. 2001;13:219-27.

25. He Y-Y, He X-J, Guo P-F, Du M-R, Shao J, Li M-Q, et al. The decidual stromal cells-secreted CCL2 induces and maintains decidual leukocytes into Th2 bias in human early pregnancy. Clinical Immunology. 2012;145:161-73.

26. Li P, Wu HL, Dong BH. Relationship between TLR4 and CCL2 expression and recurrent spontaneous abortion. Genet Mol Res. 2016;15:1-8.

27. Balogun OO, da Silva Lopes K, Ota E, Takemoto Y, Rumbold A, Takegata M, et al. In: Ota E, editor. Vitamin supplementation for preventing miscarriage. Chichester: Wiley; 2016. p. 1-130.

28. Hannan NJ, Salomonsen LA. Role of chemokines in the endometrium and in embryo implantation. Curr Opin Obstet Gynecol. 2007;19:266-72.

29. Persson M, Ekerfelt C, Jablonowska B, Jonsson Y, Ernerudh J, Jenmalm MC, et al. Immunological status in patients undergoing in vitro fertilisation: responses to hormone treatment and relationship to outcome. J Reprod Immunol. 2012;96:58-67.

Ready to submit your research? Choose BMC and benefit from:

- fast, convenient online submission

- thorough peer review by experienced researchers in your field

- rapid publication on acceptance

- support for research data, including large and complex data types

- gold Open Access which fosters wider collaboration and increased citations

- maximum visibility for your research: over $100 \mathrm{M}$ website views per year

At $\mathrm{BMC}$, research is always in progress.

Learn more biomedcentral.com/submissions 